\title{
Justifying IT Investment: Extension of a Model using a Case Study from Jordan
}

\author{
EMAD ABU-SHANAB, ${ }^{1}$ QAIS HAMMOUR ${ }^{2 *}$ and MAI TARIK AL-SEBAE ${ }^{3}$
}

${ }^{1}$ Accounting \& IS Department, CB\&E, Qatar University, Doha, Qatar. ${ }^{2}$ MIS Department, IT College, Yarmouk Universitylrbid, Jordan.

${ }^{3}$ Ministry of Education Irbid, Jordan.

\begin{abstract}
Investing in information technology is a requirement for enterprises to sustain their competitive advantage in a market that is described as changing and global. IT is a very important resource for enterprises to improve their organizational performance, but requires some justification for its costs and burdens. This study utilized an existing model and applied it on a case in Jordan by analyzing and exploring the implications of investing in IT projects. The case used is the Japan Tobacco International, where a survey was used to collect response from JTI personnel and the documents available on their portal. Two models are proposed to improve our understanding of topic and set the stage for future research. The detailed results of this study are reported with conclusions at the end.
\end{abstract}

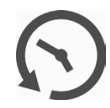

Article History

Received: 18 May 2019 Accepted: 01 July 2019

\section{Keywords}

Case Study; Investment Justification; Information Technology; Jordan;

Operational; Tactical, Strategic;

Tangible and Intangible Benefits.

\section{Introduction}

The investment in information technology results in a wide transformation toward automating the business processes in different fields in organizations. Organizations in the $21^{\text {st }}$ century adopt diverse applications and technologies to transform manual processes to automated processes to reduce their costs and increase their revenues. ${ }^{1}$
Information technology is the course of action that collects, stores, processes, and transmits data. The "term information technology" (IT) appeared in 1958 by Leavitt and Whisler, they proclaimed that "the new technology does not yet have a single established name. We shall call it information technology (IT)" [2, p. 418]. Different shapes of information technology like hardware, software,

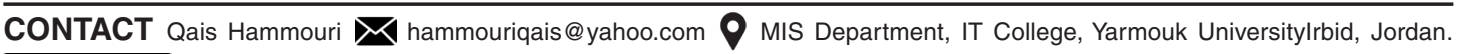
(c) (P)

(C) 2018 The Author(s). Published by Oriental Scientific Publishing Company

This is an 2 Open Access article licensed under a Creative Commons license: Attribution 4.0 International (CC-BY).

Doi: http://dx.doi.org/10.13005/ojcst12.02.03 
and networks, provide solutions for business problems. Organizations are utilizing new types of infrastructure like cloud computing and distributed systems, and advanced applications like computer aided design (CAD), computer aided manufacturing (CAM) and enterprise resource planning (ERP). ${ }^{3}$

The evolving nature of new technology as well as the fast and constant development in information and communication technology (ICT) stimulates further developments and diffusion. ${ }^{4}$ IT has had a significant influence on the way organizations function. Such developments have a crucial influence on organizations' strategies, tactics, and operational decisions. $^{5}$

This paper will explore the influence of IT investments on organizational performance utilizing a case study method. The case explored in this study is Japan Tobacco International (JTI). The structure of this paper is the following: The following section will review the literature in an aim to understand the implications of IT investments and the factors that may lead to the success or failure of such projects. The following section will cover the dimensions concluded from the literature that would relate to case under consideration. Finally, the paper will end up with conclusion and future work.

\section{Literature Review}

The employed criteria for IT investment justification can be grouped into the following categories: Strategic impact, tactical considerations, and operational performance, tangible and intangible financial and non-financial indicators. Different approaches are adopted for the purpose of evaluating IT projects and their influence on organizational performance. The reported approaches in the literature are the following: economic, strategic, operational, and analytic approaches. ${ }^{5}$

\section{Justification of IT Investment}

Quantifying the benefits of IT investment is difficult because of the high uncertainty of the factors considered in the process. The following factors contribute to the level uncertainty: global competition among companies in improving their performance and gaining competitive advantages, increasing economic pressures, radical changes in business environment, and business process reengineering. ${ }^{6}$ The information technology nature does clearly create challenges for the scientific measurement of IT investments returns. Challenges are less present in traditional long-term investments that result in competitive advantage..$^{7}$ Furthermore, IT investments are costly and make the organizations more skeptical regarding the profits and returns. IT specialists (directors and managers in charge of such investments), should analyze and explore the main factors that lead to expected returns on investment and not only the ones related to the financial results. They should also take into account the strategic advantage of the organization and creative technologies connected to IT investment with business process reengineering and organizational redesign. On the other hand, decision makers should set the main reasons that prompted the organization to invest in IT. ${ }^{8}$

There is an agreement that IT actually contributes to business value, but how it contributes to business value is uncertain. Also, understanding the nature of IT investment benefits is significant in evaluating how IT contributes to the value of the business. ${ }^{9}$ The lack of awareness of ICT nature coupled with the cash flow importance contributes to making the processes

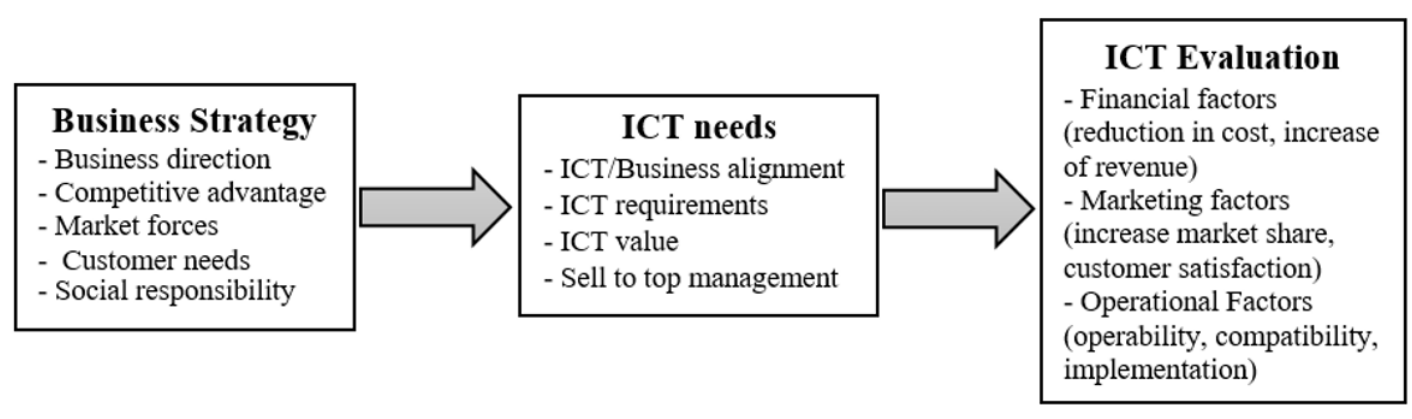

Fig.1: Process-based model for IT justification 
of evaluating its benefits burdensome and requires considerable resources. ${ }^{10}$

IT investments can comprise a tangible resource like IT assets or intangible capabilities needed. ${ }^{7}$ Such investments can influence organization's strategy by influencing both its effectiveness and efficiency. IT investment provides critical information that would either increase the investments value on other capabilities or resources, or force management toward more effective and efficient decision making.

It seems clear in the examples reported previously ${ }^{6}$ that if the evaluation is related to IT/IS services, it might need to specify more weight to "intangibles". On the other hand, we might need to specify higher weight to "tangibles" if it is in manufacturing. Such understanding means that different situations require different weights to be assigned to tangible, intangible, financial and non-financial criteria. As an example and when evaluating IT/IS marketing projects, more weight might be assigned to financial performance and intangibles such as customer satisfaction. On the other hand, the IT/IS manufacturing projects might require more weight given to non-financial performance measures such as capacity utilization, and intangibles such as flexibility. An appreciation and understanding of the intangible benefit in IT is important for IT investment continuity. ${ }^{9}$ Flexible IT infrastructure existence will enable the development and identification of key programs and applications in the organization. Such step will then improve production processes. ${ }^{11}$

\section{IT Project Importance (Success and Failure)}

Many variables have been investigated as influencers on IT success such as outsourcing, strategic planning, and IT strategic alignment. Outsourcing focuses on some of the most important issues such as IT as a competitive advantage, IT as a core competency, and company size. ${ }^{12}$ Certain application also fits with specific strategic and tactical situations. ${ }^{13}$

The evaluation of every investment (before and after being made) is very significant in determining the successful decision that the organization took ${ }^{14}$ The major barrier to justifying IT investments is having no strategic vision ${ }^{10}$ where critical issues were faced with respect to the gained strategic benefit. Also, projects budget overrun is reported as one of the many problems caused by management lack of understanding of IT costs. Such estimation uncertainty is becoming more and more important.

Sweis ${ }^{15}$ classified the factors that may lead to IS project failure into two types: managerial and technical. Poor communication, poor leadership, poor methodology and meager competencies, are the main managerial factors. Managerial factors related to the management of information system (MIS) are the most crucial factors that lead to its failure. Factors reported in the literature are the following: the organization complexity and management support. The author concludes that the high degree of customization involvement in the application, the underestimation of project schedule, and the changes in design specifications, are the three main factors that contribute to the failure of IS projects in Jordanian companies. A similar study of 105 IT firms in Jordan concluded that the most important factors influencing the success of IT projects are: poor planning, unclear goals and objectives, and changing project objectives during the execution. ${ }^{16}$

\begin{tabular}{|c|c|}
\hline \multicolumn{2}{|c|}{ Tangible Factors } \\
\hline Financial & Non-financial \\
\hline Revenue, Cost, & Customer \\
ROI, Profit, & satisfaction, \\
Payback period, & Operational \\
Total cost of & improvements, \\
ownership & image \\
\hline
\end{tabular}

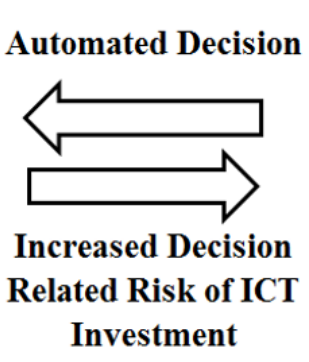

Fig.2: Risk-Value fit model (RVF Model) of ICT justification 
IT project success is assessed by using simple measures such as delivering a working system on budget, on time and to the specifications required. Such criteria are perceived as rational, objective and fact-based. However such assessment, in predicting and determining the budget needed and the time required for the system development defined by its specifications, ignores the unavoidable uncertainty. ${ }^{17}$

Reference ${ }^{18}$ examined successful system development and compared the associated factors with system success to the most associated factors with system failure. The authors concluded that the most influential factors in system success are the following: top management commitment, effective project management, project personnel knowledge/ skills and user acceptance. Such factors are directly related to the factors associated with IS failure (lack of top-management commitment to the project, lack of effective project management, lack of required knowledge/skills of project personnel, and users resistance).

Research reported many factors that are related to the success and failure of IT/IS projects. A study related to e-government projects concluded that three major categories are proposed for e-government systems success and they are: infrastructure, human, and governmental factors. ${ }^{19}$ Other researchers asserted that success or failure depends on the system type, data, size, users or certainty. It is difficult to define failure or success in general terms because it is dependent on criteria used and the stakeholders view. ${ }^{20}$ One person's failure may be another one's success. ${ }^{18}$

\section{Research Method}

This study followed a case study approach, where a case was selected to apply a framework that guides the analysis done. The framework adopted a five dimensions typology and they are: strategic impact, tactical impact, operational impact, intangible benefits, and cost related issues. ${ }^{5}$ The framework is a good tool for investment justification of IT projects.

The selected case was utilized to investigate the implications of adopting IT and its importance to the firms by using the framework. The following sections will analyze the case in details. The case is the Japan Tobacco International (JTI). This case study utilized reports published on the JTI's website and the content of the website itself, and partially for the Jordanian market. The questions addressed in this study are adopted from the framework proposed by Gunasekaran et al.,.5 Qualitative analyses on responses were applied to better understand the environment of investment in IT projects and conclude to the research objectives and goals. The main objective of this work is to better understand the investment justification in IT projects followed by a Jordanian firm. The following sections will depict the qualitative data collected and conclusions of this research.

\section{Japan Tobacco International}

Japan Tobacco International (JTI) founded as a partnership between Japan Tobacco and RJ Reynolds, where they form a group of private companies operating in 120 countries in the world and Jordan is one of them. ${ }^{21}$ The goal of $\mathrm{JTI}$ is to be the most successful and respected tobacco company in the world. JTI has a corporate strategy to increase profit through establishing outstanding brands, enhancing productivity and focusing on continuous improvement.

$\mathrm{JTI}$ realizes the downside of smoking; it does not offer its products to encourage people to smoke. JTI is interested in developing low-risk products, and it has identified its position toward smoking through six principles: openness about the risks of smoking, transparency about products, commitment to the development of reduced-risk products, prevention of youth smoking, accommodation between smokers and non-smokers, and respect for local norms and cultures. ${ }^{22}$

\section{Discussion}

In this section, we will discuss and analyze the status of JTI as a case of a study based on the main themes of our model including strategic impact, tactical impact, operational impact, intangible benefits and cost related.

\section{Strategic Impact}

The best way to ensure the effectiveness of IT investment can be achieved by looking at the technology as an essential element in achieving the company's strategy. Strategy should be clear in direction, boundaries, parameters, nature of 
environments, and connected with the objectives of the organization. ${ }^{5}$ IT/IS strategic significance in organizational performance acts a key role in determining if a particular IT/IS is needed in the organization and how it should be implemented. The strategic choices have long-term impact on IT/IS planning and implementation as well as IT/IS contribution to organizational performance. ${ }^{6}$

JTI considers technology as an important resource for achieving its strategy that is seeking to build outstanding brands, continue to enhance productivity, develop human resources as a cornerstone of growth, and sharpen the focus on responsibility and credibility of its products. ${ }^{21}$ On the other hand, the strategy of JTI is to gain a leading position in the global e-cigarette market. In 2014, JTI was successful in acquiring e-cigarette under its E-lites umbrella which was defined as "consumer products that provide an inhalable vapor by direct electrical heating of a liquid contained within the device or a replaceable cartridge". ${ }^{22}$

One of the most strategic challenges facing JTI is the illegal trade of tobacco, which is considered a global issue. Such issue influences the company's ability to control the activities such as production, import, export, purchase, and sales of its products and services. Other issues (related to legislations and the illegal trade) are the following: the high rate in taxes, difficulties facing law enforcement, difficulty to control borders, the growth of complexity in organized crime, absence of government support to eradicate this growing issue, and the adequacy of law enforcement officers' knowledge. This issue has a negative impact on both businesses and the society, where governments are challenged in overcoming the illegal trade of tobacco products. JTI succeeded in utilizing information technology as an effective solution to eliminate the illegal trade through developing a set of extensive Anti-Illicit Trade (AIT) programs in house, which represented its internal control to fight this issue. ${ }^{23}$

The main reasons that prompted the enterprise to invest in information technology are: sustaining its survival, growing in a global competitive environment, increasing its market share, and sustaining its competitive advantage. Strategic information system planning is one of the major reasons for gaining a competitive advantage. ${ }^{24} 25$ According to research related to evaluating the success of strategic information system planning in Jordan, ${ }^{26} \mathrm{JTI}$ 's success in the implementation of strategic information system planning in its strategic activities relies on a set of factors like: the clarity of strategy, the stakeholders influence and nature of social behavior, and the competitive environment. Their study utilized two case studies and they are Japan Tobacco International (JTI) and Irbid Electricity Company (IDECO).

\section{Tactical Impact}

This dimension focuses on identifying the critical success factors that will lead the company to attain its strategic objectives and goals. Tactical considerations are the following: tangible vs. intangible, performance indicators, generating data, evaluation methods, security, and involvement of senior managers. ${ }^{5}$

One of the critical success factors of JTI is the diversity of its workforce culture. The company has more than 26,000 employees from 100 different nationalities. To achieve its business objectives with high level of integrity, JTI developed a code of conduct for its employees and other stakeholders over the world. The code of conduct is presented as an integral statement regarding the organizational values, believes, roles, and responsibilities toward conducting business in compliance with corporate governance and laws. ${ }^{27}$ By enforcing such code of conduct, JTI ensures that all of its employees have the right to work in a fair environment and they have equal opportunities. They also have the needed level of commitment to establish/maintain such environment and succeed in protecting intellectual capital and personal information. ${ }^{28}$

Thomas McCoy (CEO of $\mathrm{JTI}$ ) said that "Our goal is to be the most successful and respected tobacco company in the world. The Code of Conduct is essential to achieving this." Bruno Duguay (the Chief Compliance Officer of JTI (CCO)) made the following statements: "We have made the Code as user friendly as possible by providing practical guidance and information to help you maintain the high standards JTI expects from us." 
A code of conduct mechanism is a confidential reporting concerns mechanism (RCM) that implements a robust process (like the "whistle blowing" act ) to determine any behavior or violation of JTI's compliance regulations and laws related to illicit trade internally and externally. RCM mechanism can be accessed via the company's intranet to find out the details related to illicit trade. JTI focuses on increasing awareness for its employees regarding the illicit trade issue through providing a training program for them to help minimize threats of this issue. This indicates that JTI succeeded in utilizing information technology to decrease the rate of turnover for employees. ${ }^{29}$

$\mathrm{JTI}$ is keen on improving and developing new products to meet customers' expectations as well as to achieve their strategic objectives. In December 2011, JTI signed agreement with Ploom Company to develop pocket-sized smoking devices which they called "Pax". These devices are portable vaporizers including silicon mouthpieces that can be connected with superior lip-sensing technology. Pax devices are composed of intelligent and cooling system that automatically adjust the temperature of users to optimize heat and vapor production without heating the material or producing smoke. ${ }^{30} 31$

By integrating IT with intellectual property, JTI teams utilized email tools to receive new ideas or suggestions related to new product development from persons not belonging to JTI group. Such technique is protecting the company as well as its intellectual property for talented people. ${ }^{32}$

\section{Operational Impact}

When exploring the operational considerations, the enterprise should identify the operational critical success factors to perform the daily operations. Such dimensions mean that the firm needs to measure the role of IT infrastructure in achieving business goals for each department. The process includes measuring the system and data integration, users' perceptions, servers, existing operations system, data migration, existing IT systems, and software. ${ }^{5}$

JTI tries to fight illicit trade and deter criminals from converting genuine products from the judicial supply chain. JTI has 22 factories, 5 tobacco processing facilities, 8 global flagship brands and hundreds of different products sold in millions of selling points by tens of thousands of distributors and suppliers over the world. ${ }^{33}$ This makes illegal trade a big threat and global issue to the company. In 2013, Euromonitor reported that the size of illicit tobacco trade is approximately 392 billion cigarettes per year. ${ }^{23}$ Based on that, the company has worked hard to invest in IT to protect its supply chain from illicit trade. JTI implemented the "track and trace" system, which aims at delivering its products to the intended markets. The process includes putting unique signs on the products at the master case and carton level, which enables the company to monitor the route of its products within the legitimate supply chain.

In addition to that, JTI implemented a set of integrated programs as solutions to fight illicit trade. One of these programs is "know your customer" (KYC) program which focuses on those global customers. The system is integrated with the track and trace system to form a solid base to trace the products and where they were sold. In addition to more control on operation and the fight against illicit trade, these programs are fostering customer relationship management. Other programs adopted by JTI is the "market and volume monitoring program", which investigates the market position and determine the quantity of its products that will be sold in intended markets.

JTI also has focused on programs related to its suppliers to minimize illicit trade which is known as "know your supplier program" (KYS), which helps in conducting business with all suppliers in the manufacturing, transportation, and storage activities. JTI also has implemented the "product authentication system" which provides authentication for its products; it is defined as a digital tax verification system that allows customers to check if the package is realistic or not by an SMS or telephone call. JTI employed tagging on its products (especially chemical products) by using a reader to vitrify them. JTI also implemented some security programs to monitor its products from theft during transportation and track the finished products at factories and warehouses. ${ }^{29}$

\section{Intangible Benefits}

JTI sees technology as an important tool to achieve its strategy and to conduct business effectively 
and efficiently. ${ }^{26}$ IT played a vital role in making the company a leading international tobacco product manufacturer. JTI utilized diverse IT tools and technical solutions to enable employees to establish its business goals in a legitimate framework through four core centers that will lead the company to gain its competitive advantage.

The first is the Center of Excellence (CoE), which is responsible for understanding its business goals and incorporate them into other processes and systems. The second is the Global Development Center (GDC), which is responsible for defining the strategic direction, developing and training personnel on different global business applications, and ensuring the secure access to information in compliance with laws and regulations. The third is the Global Technical Center (GTC) that assists in providing the IT infrastructure solutions to all employees, factories and markets, such as the networks, communication and collaboration tools, and workplace computing techniques. Finally, the Information Security and Risk Management (ISRM) which provides the protection for the information resources of JTI based on three words: confidentiality, integrity, and availability.

In 2002, JTI implemented its enterprise resource planning system (ERP) as one of the most significant IT projects in its history. It provides a significant contribution for the company by acquiring and integrating different business activities from all over the world into its wide system. Examples for such application are: Gallaher, acquired in 2007 to establish JTI position in UK; and Leaf Tobacco Supplier Group acquired in 2009 to create a New Leaf Tobacco Sourcing Company with US Leaf Tobacco Supplier. On the other hand, it enhanced the human resources operations such as recruitment, selection, training and development, motivation, maintenance, and assigning and retaining a team that shares aspiring goals of the company. ${ }^{34}$ Research in Jordan indicated that ERP systems are vital applications that are associated with operational improvements, and information quality. ${ }^{4}$

JTI utilized its website to improve the quality of its products and services to the public by providing specific tools that enable customers and suppliers to submit and share their suggestions and ideas. Such venue improved JTI's position in relation to product feedback, media relations, business ethics, career and investor contacts, and corporate social responsibility. Some of these tools have positive impact on JTI's stakeholders in understanding their users and legal requirements. ${ }^{32}$ On the other hand, JTI utilized social media tools such as Facebook and Linkedln for getting people within a company to communicate, collaborate, and share their ideas and experiences that can lead to problem solving and create new ways of doing business.

JTI also developed an internal communication tool (called Engage) that enables employees to create a specific profile, where they can share their opinions, documents, and ideas on specific projects based on their role and expertise. Blanca Garcia, the project manager of Engage platform, declares that: "If traditional communication was a flat sheet of paper, a collaboration platform would be more like origami. There is overlap, different levels, it is multidimensional. With more traditional communication, such as email, two people can share ideas. With a platform like Engage, there are no limits on how many people participate in that conversation". ${ }^{35}$

JTI developed enterprise portals to make sure its business processes are completed according to standards. Such portals consisted of content management, business intelligent, data warehouse, and data management. Such tools assist the company in meeting its business needs with more security. For example, JTI developed a certification program for its suppliers who are willing to work with JTI. Suppliers are requested to provide the required information about their products and services through a dedicated portal during the bidding process. If the products and services offered by suppliers meet the certification program specifications and standards, the company may conduct the transaction. The online portals help the company in providing high quality products with lower cost, improve the relationship with suppliers, and minimize illicit trade. ${ }^{23}$

\section{Cost Related}

Measuring the benefits of IT is one of the challenges facing most companies. Reference. ${ }^{36}$ examined the factors that enable companies to predict the benefits of intangible assets and found that research and development are the most important factor followed 
by advertising expenses. On the other hand, they found that company size, growth, trading volume, equity issuance, and perceived mispricing have a positive impact on predicting intangible benefits.

Return on investment (ROI) is not an adequate tool for measuring intangible benefits of IT. ${ }^{5} \mathrm{In} \mathrm{JTI}$, intangible assets are calculated by using a cost model and are stated at cost less accumulated amortization and accumulated impairment losses. Intangible assets are treated separately, and measured at cost at the initial recognition and the costs of intangible assets acquired through business combinations with value at the acquisition date. Expenditures on internally generated intangible assets are estimated as expense in the period when incurred. An exception is the development expenses that satisfy the capitalization criteria mentioned.

Intangible assets with finite productive life cycle are amortized using a straight-line method over their estimated useful life and are tested for impairment whenever there is any indication of impairment. The estimated useful life and amortization method of intangible assets with finite useful life are reviewed at the end of each fiscal year, and any changes in estimate would be accounted for future estimation. The estimated useful life of major intangible assets with finite useful life as follows: Trademarks for 20 years and Software for 5 years.

Intangible assets with indefinite useful life and intangible assets that are not ready to use are not amortized. Still, they are tested individually for impairment or annually by cash-generating unit or whenever there is any indication of impairment. ${ }^{37}$

Since 2014, JTI has developed a formula which is known as the "Adjusted Operating Profit". The formula is considered a key performance indicator to improve business investment management and its revenue and facilitate the process of benchmarking performance with other industry players. Adjusted Operating Profit (AOP) includes the following calculations. $^{38}$

AOP $=$ Operating profit + amortization cost of acquired intangibles + adjustment items

The previous formula estimates the "Adjustment
Items" (income and costs) in the following manner

$\mathrm{Al}=$ impairment losses on goodwill \pm restructuring income and costs \pm others

\section{Conclusion and Future Work}

It is vital for businesses to better understand the factors that influence IT projects success and failure. Still businesses are not always keen on success or failure as they try to benefit from their investment in IT ventures in the best manner. Such direction requires a solid ground for measuring the benefits of implementing IT projects and investing in ICT.

This work aimed at exploring the importance of investing in IT projects. This research adopted a case study method focusing on Japan Tobacco International (JTI). Also, this study utilized a framework guided be previous work. ${ }^{5}$ The decision of investing in IT must be aligned to the organizational strategy and senior management should be committed to supporting the project by providing the necessary resources. On the other hand, the tactical and operational areas are considered as the most effective key performance indicators (KPI) in measuring the intangible benefits and to evaluate the success of investment of IT projects as well as to ensure that the project is implemented in consistency with firm's strategy and objectives.

Based on our deep analysis of the case and the available models and concepts in the literature, we proposed two models to help practitioners and researchers formulate a case for ICT investment. The first model (shown in Figure 1) reflects a process-based justification of IT investment. The process is founded by business strategy, where firms need to understand their direction, and their competitive situation. ICT should reflect what needs to be done to improve firm's market position and gain a sustained competitive advantage. Based on such analysis, ICT needs are formulated in alignment with firm's business strategy.

The final step in the process is the evaluation of the ICT content, where financial factors are dominating such step. We propose, based on our understanding of the topic, operational and marketing factors. It is important to understand that financial measures are not the only determining factor in the acquisition of 
ICT, even though they are the one to be discussed at the board of directors meeting.

The second proposed model holds a different perspective. Managers need to keep in mind the balance between value and fit during all the steps of ICT acquisition. The Proposed figure benefits from Gunasekaran et al.,5 \& 6 work and formulates a balance between tangible and intangible factors. Businesses need to keep in mind the two balances shown, where intangible factors embed more risk that tangible factors. On the same line, some decision are automated when they carry a tangible factor and less strategic influence. Figure 2 depicts the model.

Case study research adds value to our knowledge as it focuses on the details of the case. Benefiting from the joint picture of the firm by analyzing its website and reports, conduct interviews, and collect data through surveys, will enrich our understanding of a topic. Still, this study reflects our understanding of the survey responses and documents available from JTI's portals. Such work lacks the necessary generalizability of research and requires more cases to better understand the challenges faced by companies in justifying their investment in IT. Future work is required to support our understanding using other case studies. Also, it is useful to use other models or frameworks in exploring such dilemma, and better support the role of IT in sustaining organizational competitive advantage. Looking deeply into the two proposed models and previous literature will contribute to improved understanding of the area and improved decision making.

\section{Acknowledgement}

I wish to express my sincere appreciation and gratitude to all of the people that have contributed to the completion of this work. First of all, I had the great fortune to study under the supervision of Associate Professor Emad Abu-Shanab. I'm very grateful for his guidance, advice and encouragement. Secondly, I would like to thank both IT Department and Marketing Department in Japan Tobacco International Company for their support and guidance helped me to overcome numerous difficulties along the way.

\section{Conflicts of Interest}

No

\section{REFERENCES}

1. Macnish, K. (2012). Unblinking eyes: the ethics of automating surveillance, Ethics Inf Technol, Vol. 14(1), PP, 151-167.

2. Mehrotra, C. (2012). Ethics: "Its Importance, Role and Code in Information Technology", International Journal of Advance Research in Computer Science and Software Engineering, Vol. 2(1), 417-421.

3. Onn, C.W. and Sorooshian, S. (2013). Mini Literature Analysis on Information Technology Definition, Information and Knowledge Management, Vol. 3(2), PP, 139-140.

4. Abu-Shanab, E. \& Saleh, Z. (2014). Contributions of ERP Systems in Jordan, International Journal of Business Information Systems, Vol. 15(2), 2014, pp. 244-260.

5. Gunasekaran, A. Love, P. Rahimi, F. \& Miele, R. (2001). A Model for Investment Justification in Information Technology Projects. International Journal of Information
Management, Vol. 21(5), 349-364.

6. Gunasekaran, A. Ngai, E. W. \& McGaughey, R. E. (2006). Information technology and systems justification: A review for research and applications. European Journal of Operational Research, Vol. 173(3), PP, 957-983.

7. Drnevich, P. L. \& Croson, D. C. (2013). Information technology and business-level strategy: toward an integrated theoretical perspective. Mis Quarterly, Vol. 37(2), PP, 483-509.

8. Stewart, W. Coulson, S. \& Wilson. R. (2007). Information Technology: When it is Worth the Investment. Journal of the Communications of IIMA, Vol. 7(3), PP, 119-122.

9. Prasad, A. (2008). Information technology and business value in developing economies: A study of intangible benefits of information technology investments in Fiji. The Electronic 
Journal of Information Systems in Developing Countries, Vol 34(2), PP, 1- 11.

10. Love, P. E., \& Irani, Z. (2004). An exploratory study of information technology evaluation and benefits management practices of SMEs in the construction industry. Information \& Management, 42(1), 227-242.

11. Perez-Arostegui, M. N., Benitez-Amado, J., \& Tamayo-Torres, J. (2012). Information technology-enabled quality performance: an exploratory study. Industrial Management \& Data Systems, Vol. 112(3), PP, 502-518.

12. Peslak, A. R. (2008). Organizational information systems: rate of return and influencing variables as viewed by top financial executives. Industrial Management \& Data Systems, Vol. 108(1), pp. 43-59.

13. Abu-Shanab, E. (2004). Data Warehousing Strategies: A Strategic Alignment Perspective. A conceptual paper presented in the Proceedings of the Decision Sciences Institute Conference-Boston, USA. 2004, p. 1-6.

14. Ahmad, F., \& Arshad, N. H. (2014). Value Delivery of Information Technology Investment: A Conceptual Framework. International Journal of Computer Theory and Engineering, Vol. 6(2), PP, 150.

15. Sweis, R. (2015). An Investigation of Failure in Information Systems Projects: The Case of Jordan. Journal of Management Research, Vol. 7(1), PP, 173-185.

16. Abu-Shanab, E. \& Al-Saggar, A. (2013). Reasons Behind IT Project Failure: The Case of Jordan. A book chapter in "Business Strategies and Approaches for Effective Engineering Management" edited by Saqib Saeed, M. Ayoub Khan, Rizwan Ahmad., IGI Global, USA, (2013).

17. Cecez-Kecmanovic, D., Kautz, K., \& Abrahall, R. (2014). Reframing success and failure of information systems: a performative perspective. Mis Quarterly, Vol. 38(2), pp, 561-588.

18. Horan, P., \& Fowler, J. J. (2007). Are Information Systems' Success and Failure Factors Related?-An Exploratory Study Journal of Organizational and End User Computing, Vol. 19(2), pp, 1-22.

19. Abu-Shanab, E. \& Bataineh, L. (2014).
Challenges Facing E-government Projects: How to Avoid Failure? International Journal of Emerging Sciences, Vol. 4(4), pp. 207-217.

20. Nguyen, T. T. H., Saranto, K., Tapanainen, T., \& Ishmatova, D. (2014, January). A Review of Health Information Technology Implementation Success Factors: Importance of Regulation and Finance. In System Sciences (HICSS), 2014 47th Hawaii International Conference (pp. 2).

21. JTI (2019a), JTI-about-us, accessed by the Internet on May (2019), http:// https://www.jti. com/about-us.

22. JTI (2019b), JTI Brands, accessed by the Internet on May (2019), https://www.jti.com/ our-views

23. JTI (2019c), Anti-Illicit-Trade JTI, accessed by the Internet on May (2019), https://www. jti.com/our-views/fighting-illegal-tobacco

24. Earl, M.J. (1990). Approaches to Information System planning: Experiences in Strategic Information System Planning, the International Conference on Information Systems, PP, 191-225.

25. Silvius, A.J.G. Stoop, J. (2013). The Relationship between Strategic Information System Planning Situational Factors, Process Configuration and Success, Journal of Information Technology \& Information Management, 22(1), PP, 1-15.

26. Hammouri, Q. Shraideh, L. \& Abu-Shanab, E. (2015). Evaluating the Success of Information Strategic System Planning "Two Cases from Jordan". International Conference on Information Technology ICIT, PP, 390-396.

27. JTI (2019d), Code-Conduct, accessed by the Internet on May (2019), https://www.jti.com/ our-views/so-what-guides-someone-workingour-industry

28. JTI (2019e), Code of Conduct, accessed by the Internet on May (2019), https://www.jti. com/about-us/our-business/how-we-work

29. JTI (2019f) Fighting Contraband, accessed in May 2019, https://www.jti.com/our-views/ fctc-cop-different-perspective

30. Pax (2019), PaxVapor, accessed by the Internet on Septemper (2018), https://www. paxvapor.com/

31. JTI (2019g), Media, accessed by the Internet on May (2019), https://www.jti.com/our-views/ 
newsroom\#miappi-iframe

32. JTI (2019h), Contact, accessed by the Internet on May (2019), https://www.jti.com/ about-us/contact-us

33. JTI (2016), JTI Logistic, accessed by the Internet on May (2019), https://www. jti.com/sites/default/files/key-regulatorysubmissions-documents/expert-reports/ consumer-survey-evidence/2-expert-reportmidgley-report-23-june-2016-.pdf

34. JTI (2019i), Career Areas, accessed by the Internet on May (2019), https://www.jti.com/ careers

35. JTI (2019j), Engage, accessed by the Internet on May (2019), https://www.jti.com/ about-us/sustainability/human-rights-andlabor-practices/

36. Barth, M.E. Kasznik, R. \& McNichols, M.F. (2001). Analyst Coverage and Intangible Assets. Journal of Accounting Research, PP, 1-34.

37. JTI (2018a), Finance, accessed by the Internet on May (2019), https://www.jti.com/ sites/default/files/jt-group-2018-financialresults-2019-forecast.pdf

38. JTI (2018b), Investors, accessed by the Iternet on May (2019), https://www.jti.com/ sites/default/files/global-files/documents/ jti-annual-reports/jt-annual-report-2018.pdf 